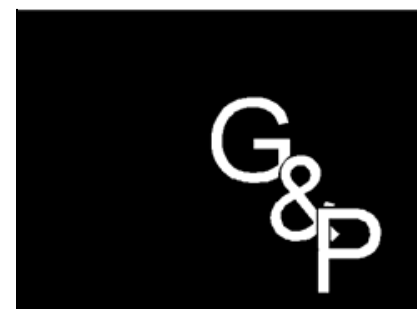

\title{
APLICAÇÃO DE QFD INTEGRANDO \\ O MODELO DE AKAO E \\ O MODELO QFD ESTENDIDO
}

\author{
Manoel Otelino da Cunha Peixoto \\ Engenharia Mecânica \\ Escola de Engenharia de São Carlos - EESC/USP \\ email: otelino@sc.usp.br \\ Luiz Cesar R. Carpinetti \\ Engenharia de Produção \\ Escola de Engenharia de São Carlos - EESC/USP \\ Av. Dr. Carlos Botelho, 1465 \\ São Carlos - SP - CEP 13560-250 \\ email: carpinet@prod.eesc.sc.usp.br
}

v.5, n.3, p. 221-238, dez. 1998

\section{Resumo}

Este artigo propõe uma abordagem de aplicação do QFD - Desdobramento da Função Qualidade - que sintetiza a versão desenvolvida por Akao (Quatro Ênfases) e a versão desenvolvida por Clausing (QFD-Estendido). A versão das Quatro Ênfases privilegia a identificação das relações entre as diversas variáveis que compõem o desenvolvimento do produto, buscando estabelecer, pelo cálculo de pesos, as variáveis prioritárias a cada matriz. O QFD-Estendido estabelece uma "hierarquia" em que as especificações da fase anterior orientam a definição das especificações da fase imediatamente posterior, indicando claramente o "caminho" a ser seguido pelo processo de tomada de decisão. Nessa versão, as decisões são tomadas dentro das próprias matrizes de QFD, que fornecem a orientação necessária para tal. Na abordagem de aplicação proposta, o produto é desdobrado pelo QFD-Estendido, sendo que algumas matrizes do QFD das Quatro Ênfases são incorporadas a esse processo e utilizadas para análises complementares. Essas análises aumentam o conhecimento sobre as variáveis do produto, orientando e facilitando a tomada de decisões durante a elaboração das matrizes. Os pontos de interseção do QFD-Estendido com os desdobramentos do QFD das Quatro Fases são apresentados e justificados. Finalmente uma discussão é feita sobre o efeito do tempo de desenvolvimento de produtos do QFD em geral e da abordagem de aplicação sendo proposta.

Palavras-chave: desdobramento da função qualidade; planejamento da qualidade, desenvolvimento de produto. 


\section{Introdução}

$\mathrm{O}$ QFD (Desdobramento da Função Qualidade) é uma metodologia que tem por objetivo auxiliar na gestão do processo de desenvolvimento (CHENG et al., 1995) de modo a manter seu foco sempre voltado para o atendimento das necessidades dos clientes. Esse gerenciamento é feito pela identificação e desdobramento das variáveis que compõem o desenvolvimento do produto (requisitos dos clientes, funções do produto, características do produto, especificações dos mecanismos e componentes, parâmetros de processo, confiabilidade do produto, custo do produto, etc.) por meio de tabelas, matrizes (a matriz é sempre resultado do cruzamento de duas tabelas, uma disposta horizontalmente e a outra disposta verticalmente) e procedimentos de extração, relação e conversão, onde:

a extração é o processo de criar uma tabela a partir de outra, ou seja, de utilizar os elementos de uma tabela como referência para se obter os elementos de outra tabela;

a relação é o processo de identificar a intensidade do relacionamento entre os dados das duas tabelas que compõem a matriz;

a conversão é o processo de transferir a importância relativa (peso) dos dados de uma tabela da matriz para os dados da outra tabela, em função da intensidade das relações existentes entre eles.

A força do QFD está em tornar tais relações (no sentido amplo, ou seja, a extração, a relação e a conversão) explícitas, permitindo a harmonização e priorização das várias decisões tomadas durante o processo de desenvolvimento do produto, bem como em potencializar o trabalho de equipe. Assim, o QFD é uma metodologia visual (utiliza-se principalmente de diagramas e matrizes), conectiva (os desdobramentos amarram as variáveis umas às outras) e priorizadora (foca as atenções da equipe nas variáveis verdadeiramente importantes). Outro aspecto importante a considerar é que, por ser uma metodologia que se baseia no trabalho coletivo, os membros da equipe desenvolvem uma compreensão comum sobre as decisões, suas razões e suas implicações, e se tornam comprometidos com iniciativas de implementar as decisões que são tomadas coletivamente.

A evolução do QFD, a partir do trabalho original de Yoji Akao, levou ao surgimento de diferentes versões da metodologia, conforme descritos na literatura (ABREU, 1997; SIVALOGANATHAN \& EVBUOWAN, 1997; AKAO, 1996; CHENG et al., 1995; CLAUSING, 1993; MALLON \& MULLIGAN, 1993; CLAUSING \& PUGH, 1991; AKAO, 1990; KING, 1989; HAUSER \& CLAUSING, 1988 e SULLIVAN, 1986).

Cabe aqui ressaltar duas dessas versões: o QFD-Estendido e o QFD das Quatro Ênfases. O QFD-Estendido foi criado por Don Clausing a partir da versão das Quatro Fases de Macabe (CHENG et al., 1995). Essa versão é descrita em CLAUSING (1993) e em CLAUSING \& PUGH (1991). O QFD das Quatro Ênfases (conforme denominação utilizada por KIENITZ, 1995) foi criada pelos Professores Akao e Mizuno e difundida pela JUSE (Union of Japanese Scientists and Engineers). Aqui no Brasil, é descrita por CHENG et al. (1995) e AKAO (1996) e, nos Estados Unidos, AKAO (1990) é referência obrigatória.

A versão do QFD-Estendido é caracterizada pela existência de quatro fases (planejamento do produto, projeto, planejamento do processo e planejamento da produção), sendo que a segunda delas é constituída de várias matrizes e as demais de apenas uma matriz (CLAUSING, 1993). A versão do QFD das quatro ênfases é caracterizada pela existência de quatro tipos de desdobramentos ou ênfases (qualidade, tecnologia, custo e confiabilidade), sendo que cada desdobramento é composto de várias matrizes.

Essas duas versões do QFD se diferenciam basicamente pela condução da execução dos desdobramentos. Isso determina como cada versão do QFD irá, prioritariamente, conduzir a atenção da equipe de desenvolvimento, se para a identificação das relações (no sentido restrito) 
existentes entre as diversas variáveis ou se para a definição de especificações, por meio da extração.

Este artigo propõe uma abordagem de aplicação da metodologia QFD que incorpora matrizes dos desdobramentos da qualidade, da tecnologia, do custo e da confiabilidade à estrutura básica de desdobramentos do QFD-Estendido. Esta abordagem, acredita-se, potencializará a metodologia QFD como gestora do processo de desenvolvimento de produtos. Como a abordagem ora proposta pode ser entendida como uma síntese das versões QFD-Estendido e QFD das Quatro Ênfases, essas versões serão brevemente analisadas.

\section{O QFD-Estendido e QFD das Quatro Ênfases}

-
CLaminando a estrutura descrita por PUGH (1991), pode-se perceber que no QFDEstendido a construção das matrizes obedece a lógica de sistema: as informações entram no sistema na primeira fase, como requisitos do cliente; são processadas durante as quatro fases em "operações” chamadas "extração, relação e conversão"; e saem em forma de informações para a produção, na última fase. Assim, nessa versão, as matrizes sempre têm uma entrada (a tabela horizontal) e uma saída (a tabela vertical). Não há entradas de dados nas fases intermediárias, a não ser pelas atividades complementares, cujas funções são apenas enriquecer a análise do processamento. Além disso, o QFD-Estendido caracteriza-se pela existência da extração e pela tomada de decisões em todas suas matrizes.

Cada matriz, em si própria, também funciona como um sistema. Porém sua entrada é sempre a saída da matriz anterior. Essa regra torna o caminho da tomada de decisões explícito, criando uma "hierarquia" na qual as decisões da matriz anterior direcionam e determinam as decisões tomadas na matriz em análise. Isso é muito útil para a identificação de características e parâmetros (todos com seus respectivos valores), pois “obriga” as decisões tomadas a cada estágio do processo de desenvolvimento serem sempre direcionadas à concretização das decisões tomadas no estágio precedente (e portanto, facilita a harmonização e consistência dessas decisões). Deve-se salientar que esse processo de tomada de decisões, obviamente, não exclui a revisão crítica de atividades passadas a partir da luz de atividades presentes.

Por fim, pode-se destacar que, nessa versão, as decisões são tomadas “dentro” das respectivas matrizes, e não em atividades do desenvolvimento de produtos externas ao QFD. Todas as matrizes do QFD-Estendido, inclusive, cruzam características extraídas com “características requisitos”, facilitando assim a definição (por extração) dos valores das especificações das primeiras. Esse fator foca a equipe na hierarquia da tomada de decisões, comentada acima. Podese concluir, portanto, que esta versão tem como ponto forte a fixação de especificações parâmetros e valores de qualidade projetada.

Por outro lado, a versão das Quatro Ênfases é composta, segundo CHENG et al. (1995), de dois tipos de desdobramento: o Desdobramento da Função Qualidade no Sentido Restrito (QFDr) e o Desdobramento da Qualidade (QD). O QFDr é o desdobramento do trabalho. O QD é o desdobramento do produto.

Na versão das Quatro Ênfases o trabalho é iniciado pelo seu próprio planejamento. Esse planejamento é dividido em duas partes: o planejamento dos desdobramentos e o planejamento das atividades.

O planejamento dos desdobramentos é feito a partir da definição do Modelo Conceitual. O Modelo Conceitual, segundo CHENG et al. (1995), é a definição das matrizes e tabelas que constituirão os desdobramentos, pela elaboração gráfica do "caminho" que o desenvolvimento deve percorrer.

O planejamento das atividades é feito pelo QFDr. O QFDr é a definição das fases, processos e atividades do desenvolvimento do produto, por meio de um processo de desdobramento utilizando o Diagrama em Árvore. 
Após planejado o trabalho de desenvolvimento deve-se iniciar a execução dos desdobramentos, que são a essência do QD, conforme o modelo conceitual proposto. No QD, o desenvolvimento do produto é analisado sob quatro ênfases:

O Desdobramento da Qualidade;

O Desdobramento da Tecnologia;

O Desdobramento de Custos e;

O Desdobramento da Confiabilidade.

Por fim, a versão das Quatro Ênfases define os documentos que transmitem para a produção os padrões estabelecidos no desenvolvimento do produto. São eles:

1) Tabela de Garantia de Qualidade;

2) Fluxograma de Processo;

3) Tabela de Análise de Processos Críticos;

4) Padrão Técnico de Processo.

É importante frisar que nas referências dessa versão estudadas pelos autores desse artigo (AKAO, 1996: AKAO, 1990; CHENG et al., 1995), poucos são os exemplos encontrados de ocorrência explícita de extração de características, especificações ou parâmetros, ocorridos em matrizes que não sejam a Matriz da Qualidade (denominação dada à Casa da Qualidade no QFD das Quatro Ênfases). Mesmo assim, nos poucos exemplos encontrados, não há o cruzamento de "Característica Extraída" com "Característica Requisito", o que impede a clara extração dos valores das características, ou dos parâmetros de processo. Desse modo, pode-se afirmar que as matrizes do QFD das Quatro Ênfases, exceto a Matriz da Qualidade, são utilizadas, de modo geral, para determinar prioridades a partir da identificação de relações (no sentido restrito).

A partir do exposto, pode-se dizer que a lógica que rege a versão das Quatro Ênfases é a identificação das relações de todas as variáveis, em diferentes fases, dando à equipe de desenvolvimento uma visão geral de como cada decisão afeta as demais. Essa versão de QFD sistematiza a compreensão dessas relações pelas matrizes do Modelo Conceitual. Sistematiza também a definição de prioridades sob os variados pontos de vista, a partir do momento que explora todas as relações entre as variáveis. Por exemplo, pode-se perceber que um determinado processo é prioritário sob o ponto de vista das suas relações com os componentes, e perceber que outro processo é prioritário porque suas falhas refletem muito fortemente nas falhas do produto.

Por outro lado, esta versão de QFD não sistematiza a definição das características e especificações dos mecanismos e componentes, nem a definição dos parâmetros dos processos. Muito menos, sistematiza a extração de valores para as variáveis citadas anteriormente. Assim, a lógica de condução dos desdobramentos das duas versões se diferenciam basicamente pelos seguintes aspectos:

1. A versão QFD-Estendido privilegia a extração. Em todas suas matrizes uma das tabelas sempre orienta a identificação das variáveis (e dos seus respectivos valores) da outra tabela. Assim privilegiam a definição da Qualidade Projetada, ou seja, a definição dos valores dos parâmetros. Aqui fica bastante explícito o "caminho" da tomada de decisão, pois as decisões tomadas na matriz anterior se tornam requisitos da matriz seguinte. Essa versão sistematiza a tomada de decisões dentro das próprias matrizes de QFD. Dessa forma, seu ponto forte é a condução da tomada de decisões.

2. A versão das Quatro Ênfases privilegia a identificação das relações e a conversão. Na construção de suas matrizes a extração não é muito usada. Aqui, busca-se tornar evidente como cada variável afeta as demais. O mais importante é estabelecer a importância relativa, ou seja, os pesos absoluto e relativo, e, por meio deles, identificar o valor relativo, ou seja o grau de prioridade. Essa versão sistematiza as análises complementares à fixação especificações características e parâmetros e a determinação de prioridades. Dessa forma, seu ponto forte é a possibilidade de cruzar as tabelas que forem necessárias. Ou seja, pode-se afirmar que o QFD-Estendido é 
um condutor da determinação de parâmetros e o QFD das Quatro Ênfases é um condutor da identificação de prioridades.

A partir dessa análise, entendem os autores que a aplicação da metodologia QFD pode ser feita por uma abordagem em que, pela síntese das duas versões, seja possível enriquecer o benefício da aplicação do QFD no desenvolvimento de produtos e processos.

\section{Proposta de Aplicação da Metodologia QFD}

A abordagem de aplicação ora proposta compreende o planejamento do desenvolvimento do produto, pelo QFDr e pelo Modelo Conceitual (conforme descritos em AKAO, 1996; AKAO, 1990 e CHENG et al, 1995); a incorporação de matrizes propostas pelo QFD das Quatro Ênfases na execução das fases de desdobramentos do produto feita pelo QFDEstendido; e a transmissão dos padrões, utilizando os documentos propostos pelo modelo das Quatro Ênfases.

Nessa abordagem, o produto é desdobrado conforme a versão do QFD-Estendido, mas são também executadas matrizes que permitem análises complementares pela ótica das Quatro Ênfases de Akao, gerando interações entre o desdobramento do produto (QFD-Estendido) e os desdobramentos da Qualidade e da Tecnologia, do Custo, e da Confiabilidade.

O desdobramento do produto (Figura 1), que corresponde ao QFD-Estendido, permite planejar o desenvolvimento encadeando a tomada de decisões, de modo que as decisões tomadas em estágios anteriores do desenvolvimento orientem as decisões tomadas em estágios posteriores. As outras ênfases, por serem adaptações dos desdobramentos da versão das Quatro Ênfases, serão chamados daqui para frente de desdobramentos analíticos.

O desdobramento da qualidade e tecnologia tem por objetivos: (a) sistematizar o processo de engenharia simultânea do desenvolvimento do produto, permitindo correlações de requisitos e características da qualidade com funções, mecanismos, componentes, processos e matérias-primas; e (b) identificar e remover prematuramente gargalos de engenharia (conforme o conceito descrito por AKAO, 1996; AKAO, 1990 e CHENG et al., 1995).

O desdobramento do custo visa a identificação e remoção prematura de gargalos de custos, sob a ótica de análise de valor. Também permite identificar valores de qualidade para as características técnicas do produto que viabilizem, sem muitas dificuldades, a obtenção dos custos objetivados.

O desdobramento da confiabilidade tem por objetivo entender como melhorar a confiabilidade do produto pela definição das suas características (e seus respectivos valores).

Deve-se observar, porém, que existe uma "hierarquia" entre as quatro ênfases. É o desdobramento do produto que "puxa" o ritmo do desenvolvimento do produto. Os demais desdobramentos são complementares a ele, sendo executados somente quando "solicitados" pelo desdobramento do produto. É importante ressaltar que, devido a essa "hierarquia", os desdobramentos analíticos tem uma seqüência de execução diferente daquela descrita em AKAO (1996), AKAO (1990) e CHENG et al. (1995).

A Figura 1 apresenta as fases de desdobramentos do produto e as respectivas matrizes. Cabe ressaltar que neste artigo será considerada, na fase de projeto, apenas a Matriz de Projeto dos Componentes, diferentemente do QFDEstendido completo que inclui nessa fase a Matriz de Projeto do Sistema e a Matriz de Projeto do Mecanismo. Essa simplificação se justifica porque as etapas "Matriz de Projeto do Sistema", "Matriz de Projeto do Mecanismo" e "Matriz de Projeto dos Componentes" são desdobramentos da fase de projeto, necessários somente para produtos que apresentem vários níveis de agregação. Como a maioria dos produtos, mesmo quando utilizam tecnologia dinâmica, não requerem o desdobramento da fase de projeto em três níveis de agregação, essa 


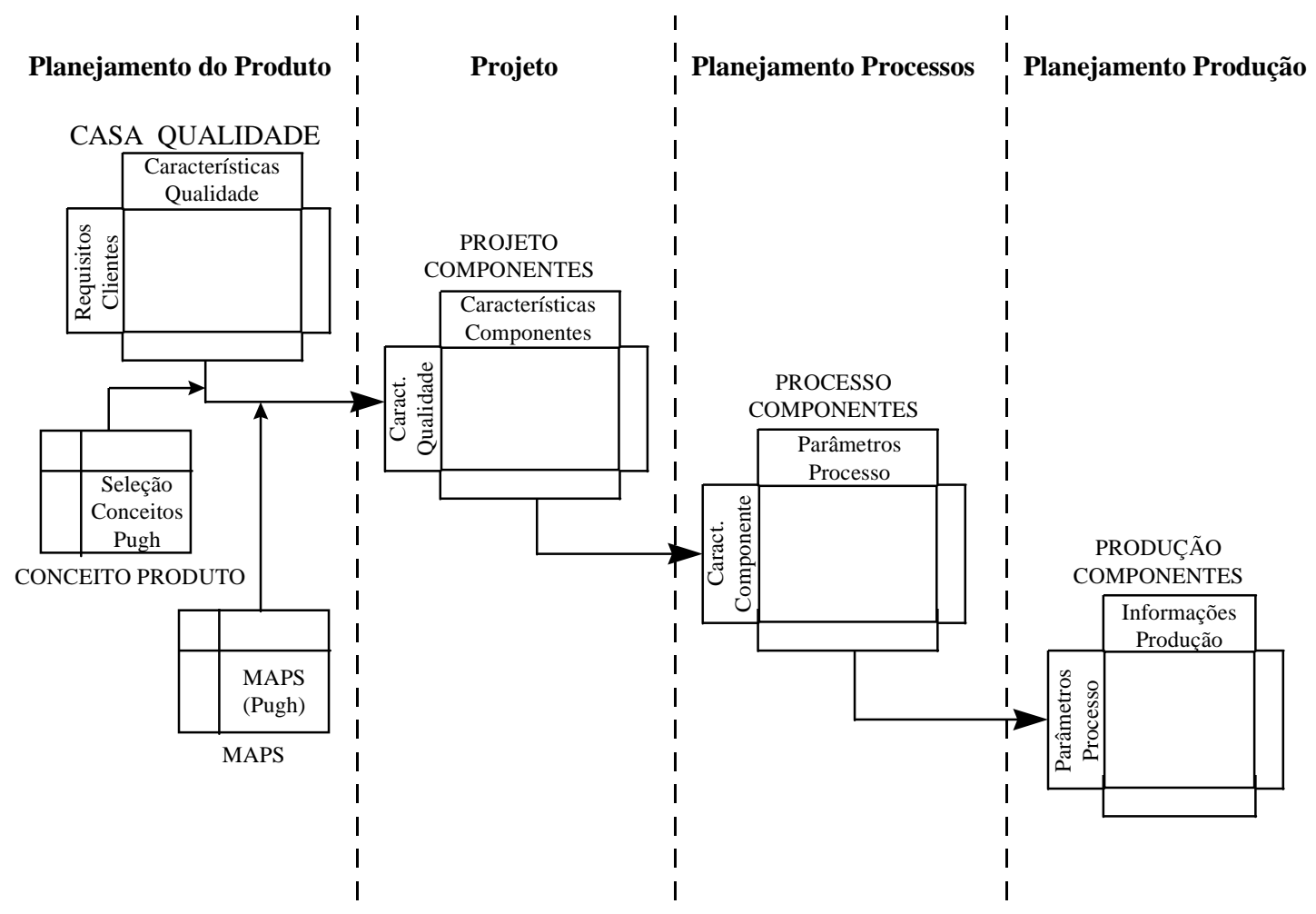

Figura 1 - O QFD-Estendido (ou desdobramento do produto) na abordagem proposta

simplificação facilita o entendimento e também é de aplicação mais genérica.

A seguir será descrita a interseção entre os desdobramento do produto e os desdobramentos analíticos.

\subsection{Matriz de Especificação do Produto (Total System Matrix)}

A Matriz de Especificação do Produto (Total System Matrix) corresponde à Casa da Qualidade (Figura 2). É, portanto, composta do cruzamento da Tabela dos Requisitos dos Clientes (entrada) com a Tabela das Características da Qualidade (saída). A primeira identifica quais são as necessidades dos clientes que devem ser atendidas pelo produto e a segunda identifica quais são as características do produto que respondem às necessidades dos clientes indicadas. Os elementos (ou áreas) da Casa da Qualidade que intercedem (ou "solicitam") a execução dos desdobramentos analíticos e os respectivos desdobramentos são indicados a seguir:

a) Peso Relativo dos Requisitos dos Clientes. Após calculados os pesos relativos dos requisitos dos clientes (ou seja, terminada a execução de toda a Tabela dos Requisitos dos Clientes) devese elaborar o desdobramento das funções e a Matriz Requisitos dos Clientes versus Funções, que correspondem aos passos 1 e 2 do desdobramento da qualidade e tecnologia (ver Figura 2). A Matriz Requisitos dos Clientes versus Funções possibilita identificar os requisitos dos clientes que correspondem às qualidades óbvias, e que por isso não foram listados. Dessa forma, obtém-se a garantia que esses requisitos não serão negligenciados (AKAO, 1990).

b) Características de Qualidade. A extração das características da qualidade deve ser precedida da elaboração da Tabela de Desdobramento da Árvore de Falhas do Produto (FTA) e da Matriz Requisitos dos Clientes versus FTA do Produto (passos 1 e 2 do desdobramento da 
confiabilidade. Ver Figura 2). A intenção nesse momento é, pelo conhecimento das falhas do produto que afetam o atendimento dos requisitos dos clientes mais importantes (e qual é a gravidade dessas falhas), facilitar a identificação das características técnicas do produto relacionadas à confiabilidade.

Após extraídas as características de qualidade, deve-se elaborar a matriz Funções versus Características de Qualidade (passo 3 do desdobramento da qualidade e tecnologia. Ver Figura 2.), que irá garantir que nenhuma característica que atende às qualidades exigidas óbvias foi descartada ou esquecida. Essa matriz complementa a análise da matriz "Requisitos dos Clientes versus Funções”, elaborada no passo 2 do desdobramento da qualidade e tecnologia (ver Figura 2).

c) Fator de Dificuldade Técnica. Esse fator é uma nota que expressa a dificuldade tecnológica que a empresa terá para obter o valor determinado para a qualidade projetada das características da qualidade, com a confiabilidade projetada e com o custo objetivado (AKAO, 1996 e AKAO, 1990). Por isso, ele expressa quais as características que provavelmente exigirão maior comprometimento de esforços e recursos na obtenção dos seus valores-meta (CLAUSING, 1993).

O fator de dificuldade técnica é usado na matriz da qualidade para corrigir o peso das características da qualidade. Entretanto, essa correção do peso de cada característica da qualidade pode ser feita de duas maneiras: ou se atribui maior importância àquelas características que implicam em uma menor dificuldade técnica, ou se atribui maior importância àquelas características que, para o seu atendimento, implicam em uma maior dificuldade técnica.

Neste artigo, o fator de dificuldade técnica é usado de forma que seja atribuído maior importância àquelas características que, para o seu atendimento, impliquem em uma maior dificuldade técnica. Nesse caso, a escala do fator é proporcional à dificuldade de se obter os valores-meta, onde o valor baixo da escala significa a menor dificuldade técnica e o valor alto da escala significa a maior dificuldade de sucesso (AKAO, 1996 e CLAUSING, 1993). Esta alternativa deve ser usada por empresas que desenvolvam produtos com longos ciclos de vida. Tais empresas, utilizando uma escala do fator de dificuldade técnica diretamente proporcional à dificuldade de se obter os valores-meta, fazem com que sejam priorizadas, na fase de planejamento do produto, aquelas características técnicas difíceis de ser incorporadas ao produto, ou que exigirão maior comprometimento de esforços e recursos na obtenção dos seus valores-meta. Devem também utilizar a escala proporcional à dificuldade técnica, as empresas que, mesmo tendo produtos de curto ciclo de vida, trabalhem com desenvolvimento de tecnologia paralelo ao desenvolvimento de produtos, conforme proposto por CLAUSING (1993).

Dessa forma, na abordagem ora proposta, a definição do fator de dificuldade técnica é precedida da execução das seguintes matrizes:

desdobramento da qualidade e tecnologia: feito por meio dos passos 2 a 7 do desdobramento da qualidade e tecnologia, conforme indicados na Figura 2. Essas matrizes correspondem a uma adaptação do desdobramento da qualidade e tecnologia, descrito em AKAO (1996), AKAO (1990) e CHENG et al. (1995), para empresas que não consideram o nível de mecanismos no desenvolvimento do seus produtos. Convém ressaltar que as duas primeiras matrizes já foram elaboradas nos itens A e B, respectivamente, e que portanto neste estágio serão apenas analisadas.

$\mathrm{Na}$ abordagem proposta, o desdobramento da qualidade e tecnologia busca prevenir a ocorrência de gargalos de engenharia. Tal prevenção é feita pela identificação prematura de quanto pode-se incrementar a qualidade projetada das características de qualidade utilizando-se as tecnologias de produto e de processo dominadas pela empresa.

desdobramento da confiabilidade: feito por meio dos passos 2 a 10 para o desdobramento da confiabilidade, como indicados na Figura 2. Esses passos correspondem à identificação 


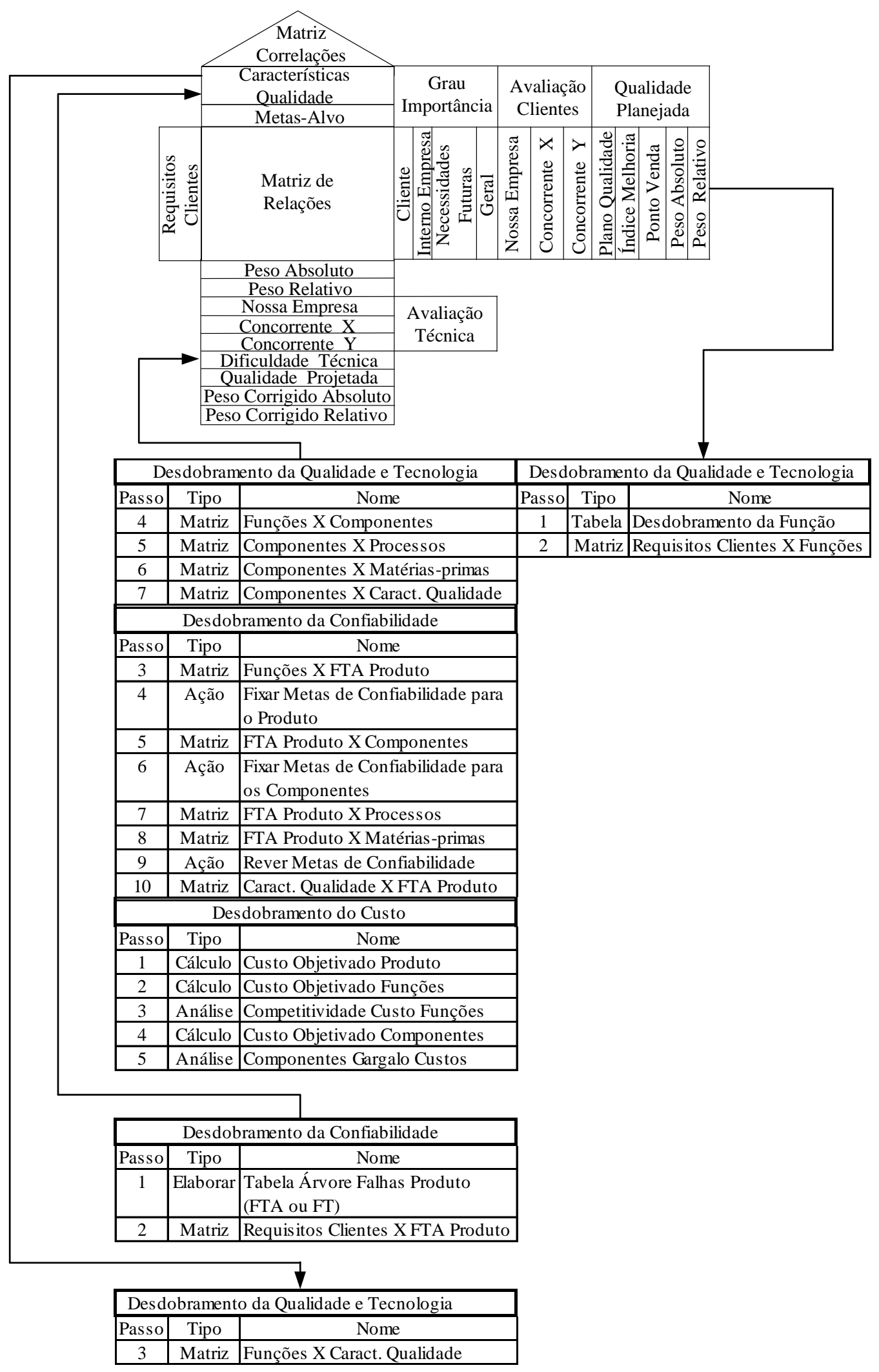

Figura 2 - Demonstração das interseções da Casa da Qualidade com os desdobramentos analíticos 
dos gargalos de confiabilidade, conforme uma adaptação da proposta de AKAO (1996), AKAO (1990) e CHENG et al. (1990) à realidade de empresas que não utilizam o nível de agregação de mecanismos. Porém, na abordagem proposta, o desdobramento da confiabilidade busca identificar o quanto será difícil melhorar a confiabilidade do atual produto e, principalmente, permite estabelecer metas de confiabilidade para o produto em desenvolvimento que sejam compatíveis com as tecnologias de produto e processo dominadas pela empresa. A seguir vai-se comentar alguns pontos desse desdobramento que requerem uma melhor explanação.

Na Matriz Requisitos dos Clientes versus FTA do Produto (passo 2, Figura 2) deve-se calcular os pesos das falhas sob três pontos de vista: pela conversão do peso dos requisitos dos clientes, pela taxa de ocorrência e pela criticidade, conforme indicado em AKAO (1996) e em CHENG et al (1995).

A Matriz Funções versus FTA do Produto (passo 3, Figura 2) permite compreender quanto e como cada falha compromete o perfeito funcionamento deste produto, sendo este entendido como o desempenho de suas funções do modo planejado. Desse modo, deve-se converter os pesos das funções em pesos das falhas, para priorizar essas últimas sob o ponto de vista da engenharia.

As metas de confiabilidade (passo 4, Figura 2) para o produto devem ser fixadas a partir da análise dos pesos das falhas calculados nas duas matrizes anteriores. AKAO (1996) cita como metas de confiabilidade: taxa de falhas e tempo médio de falhas.

$\mathrm{O}$ alocamento das metas de confiabilidade para os componentes (passo 6, Figura 2) significa que as metas de confiabilidade do produto devem ser "distribuídas" para os componentes, de modo a determinar quanto cada componente pode contribuir para as falhas do produto.

Alocadas as metas de confiabilidade aos componentes e conhecidas as limitações tecnológicas (produto e processos) para melhorar cada componente, obtida pelo desdobramento da qualidade e tecnologia, pode-se identificar a dificuldade de produzir componentes capazes de atingir as metas de confiabilidade alocadas a eles.

As matrizes FTA do Produto versus Processos e FTA do Produto versus Matérias-primas (passos 7 e 8, respectivamente. Ver Figura 2.) permitem identificar como os processos e os materiais limitam a melhoria da confiabilidade dos componentes.

A Matriz Características de Qualidade versus FTA do Produto (passo 10, Figura 2) permite relacionar as características de qualidade com as falhas do produto. Desse modo, essa matriz facilita a identificação do quanto a qualidade projetada de cada características de qualidade precisa ser alterada para permitir a concretização das metas de confiabilidade.

desdobramento do custo (Figura 2): determina os componentes gargalo de custos, ou seja, aqueles cujo custo real é superior ao custo objetivado, esse último calculado via análise de valor. Na abordagem proposta, além da identificação dos gargalos de custos, busca-se identificar quais serão os valores de qualidade projetada para as características de qualidade que viabilizarão, sem muitas dificuldades, os custos objetivados.

As definições do Custo Objetivado do Produto (passo 1, Figura 2) e do Custo Objetivado das Funções (passo 2, Figura 2) não serão detalhadas aqui, visto que são feitas conforme descritas em AKAO (1996), AKAO (1990) e CHENG et al. (1995). A avaliação da competitividade das funções (passo 3, Figura 2), porém, precisa ser discutida.

Segundo CLAUSING (1993), a avaliação da competitividade (passo3, Figura 2) de um produto deve ser feita comparando o custo de suas funções. Isso porque produtos diferentes podem ter componentes diferentes desempenhando a mesma função, o que inviabilizaria a comparação pura dos componentes. Além disso, o cliente "compra” o desempenho de 
funções e não componentes. Dessa forma, o produto necessita ser competitivo em sua funções para ter sucesso no mercado. Assim, fazendo-se uma avaliação da competitividade das funções do produto, obtém-se a oportunidade de melhorar o desempenho competitivo deste. Obviamente, a redução do custo objetivado das funções não competitivas precisa refletir na redução do custo dos componentes. Isso implica que o custo objetivado de cada função deverá ser distribuído aos componentes pelo método de distribuição proporcional de pontos, descrito por AKAO (1996).

A análise dos componentes gargalos de custo é feita, na abordagem proposta, comparando os custos objetivados com os custos reais (ou orçados) do produto atualmente existente. Aqueles que tiverem grandes diferenças provavelmente representam gargalos de custos. A equipe deve, então, avaliar a dificuldade real de atingir os custos objetivados, utilizando-se as tecnologias de produto e de processos atualmente dominadas pela empresa. O conhecimento dessa dificuldade possibilita determinar valores-meta para as características de qualidade que viabilizarão uma redução significativa de custos. Por fim, cabe discutir a utilização dos custos reais (ou orçados) do produto existente para determinar os gargalos de custo. O custo do produto existente é uma referência para determinar prematuramente o esforço necessário para a obtenção dos custos objetivados. Desse modo, deve-se utilizar o custo real (ou orçado) para determinar antecipadamente os possíveis gargalos de custo, antes mesmo de iniciar o projeto dos componentes.

\subsection{Seleção do Conceito do Produto (Total System Concept Selection)}

O Conceito do Produto deve ser selecionado utilizando-se o Processo de Seleção de Conceitos de Pugh, conforme descrito em CLAUSING (1993), inclusive na abordagem ora proposta. Isso porque, como não haverá remoção de gar- galos de engenharia, não há interseções entre essa etapa do desdobramento do produto e os desdobramentos analíticos. É importante notar, porém, que os conceitos passíveis de serem escolhidos são apenas aqueles cujas tecnologias de produção são dominadas pela empresa, visto que não haverá remoção de gargalo de engenharia durante o processo de desenvolvimento do produto. Aqui está embutido, portanto, o conceito de reutilização (no original em inglês, "reusability") conforme definido por CLAUSING (1993). Nesse caso, os conceitos possíveis são: o conceito utilizado no atual produto da empresa, ou o conceito utilizado em outro produto da empresa, ou, ainda, um novo conceito já dominado pela empresa mas ainda não utilizado em nenhum de seus produtos (nova tecnologia).

\subsection{Elaboração da Matriz de Projeto dos Componentes (Piece-Part Design Matrix)}

Na Matriz de Projeto dos Componentes (Piece-Part Design Matrix) desdobra-se o produto em componentes. Os requisitos dessa matriz (linhas) são as características de qualidade (do produto) decididas na matriz anterior. As colunas dessa matriz são preenchidas com as características dos componentes. Na Matriz de Projeto dos Componentes, segundo CLAUSING (1993), devem constar todos os componentes a serem desenvolvidos, embora não conste os componentes a serem reutilizados ("reusability"). A identificação dos componentes que terão que ser desenvolvidos é auxiliada pelos desdobramentos analíticos, da forma que se segue:

O conhecimento já acumulado no desdobramento da qualidade e tecnologia (Figura 2) permite identificar aqueles componentes que terão suas especificações "apertadas", mesmo que tais mudanças não configurem uma migração para um conceito ainda não utilizado pela empresa. Esses serão desenvolvidos ou revistos, se não puderem ser "aproveitados" de outro produto, dentro do conceito de "reusability", descrito por CLAUSING (1993). 
O conhecimento já acumulado no desdobramento da confiabilidade (Figura 2) permitirá a identificação dos componentes que mais comprometem a confiabilidade do produto (Figura 2). De modo geral, pode-se dizer que os componentes que apresentam elevados pesos convertidos das falhas, devem ser melhorados em sua confiabilidade, o que implica em seu desenvolvimento (se não puderem ser "aproveitados" de outro produto no sentido de "reusability", conforme descrita por CLAUSING, 1993).

O conhecimento já acumulado no desdobramento do custo (Figura 2) determina os componentes que devem ser reprojetados ou substituídos ("reusability"), buscando uma redução de custo. AKAO (1996), porém, alerta que nem todos componentes gargalos de custo (que é uma análise de valor) terão real possibilidade de ter seu custo de produção reduzido. Esses componentes deverão ser identificados prematuramente para que não sejam desperdiçados recursos em planos de redução de custos estéreis.

A opção por um novo conceito de produto (fase 2 do desdobramento do produto) também implica em desenvolvimento obrigatório dos componentes que terão sua tecnologia modificada.

Após definidos os componentes que serão desenvolvidos, deve-se fazer a Seleção de Materiais e Processos (ou Material and Process Selection, MAPS, utilizada por CLAUSING, 1993). Segundo CLAUSING (1993), a escolha antecipada dos materiais e processos tem sido um fator de sucesso no desenvolvimento de produtos, visto que ela libera tempo para o projeto detalhado. CLAUSING (1993), inclusive, posiciona a Seleção de Materiais e Processos como último passo da fase Matriz de Projeto dos Mecanismos. Porém, no presente trabalho, o produto não será analisado nesse nível de agregação, visto que a complexidade da maioria dos produtos não exige o esforço de elaboração das matrizes correspondentes. Considerando a importância de se executar prematuramente a Seleção de Materiais e Processos, optou-se por incluí-la como primeira atividade da execução da Matriz de Projeto dos Componentes. Isso significa que a equipe de QFD deve escolher, nesse momento, todos materiais e processos necessários para a confecção dos componentes, utilizando qualquer uma das diversas ferramentas disponíveis para esse fim. CLAUSING (1993) cita especificamente duas ferramentas: a Metodologia Boothroyd-Dewhurst (descrita em BOOTHROYD, 1992) e o Processo de Seleção de Conceitos de Pugh. Segundo ele, CLAUSING (1993), para a maioria dos propósitos a segunda ferramenta é o método mais corrente.

Na abordagem ora proposta, a MAPS (Figura 3) pode ser auxiliada pela análise dos desdobramentos analíticos abaixo relacionados:

Desdobramento da Confiabilidade. O conhecimento acumulado na elaboração das Matrizes FTA do Produto versus Processos (passo 7, Figura 3) e FTA do Produto versus Matérias-primas (passo 8, Figura 3), ambas já elaboradas na Matriz de Especificação do Produto (seção 3.1), fornece informações que permitem identificar, prematuramente, a intensidade com que cada opção de processo e matéria-prima pode influenciar a ocorrência de falhas no produto, e a gravidade dessas falhas.

Desdobramento do Custo. A idéia é identificar materiais e processos que possam, pelo menos em princípio, atender os custos objetivados para o produto. Isso implica no prévio conhecimento dos custos objetivados para os componentes (passo 4, já executado na Matriz de Especificação do Produto, seção 3.1), para orientar a seleção de materiais e processos que não exijam grandes esforços para redução de custos, em etapas posteriores do desenvolvimento do produto.

Durante a elaboração da matriz de Projeto dos Componentes, propriamente dita, tem-se a interseção do desdobramento do produto com os desdobramentos analíticos na extração das características dos componentes (Figura 4). Na abordagem ora proposta, essa extração se dá de quatro formas: 


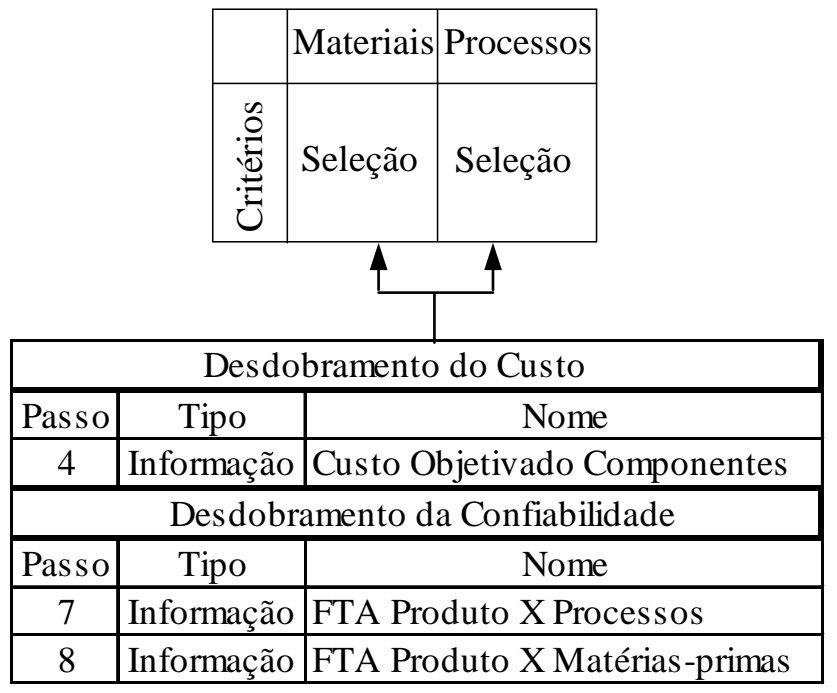

Figura 3 - Demonstração da interseção entre a Seleção de Materiais e Processos (MAPS) e os desdobramentos analíticos

análise das características dos componentes críticos para a confiabilidade. Essas características são identificadas pela elaboração de FMEA para os componentes críticos (passo 11 do desdobramento da confiabilidade, Figura 4). Na abordagem proposta, um componente será considerado crítico quando tiver pelo menos um peso convertido das falhas do produto com valor significativo.

A elaboração de FMEA permite compreender profundamente como os componentes falham e como as falhas dos componentes causam falhas do produto. Assim, torna-se possível a conversão das falhas dos componentes (qualidades negativas) em características dos componentes (qualidades positivas). Também torna-se possível extrair metas para as falhas dos componentes a partir das metas das falhas de produto. Aqui, então, torna-se necessário distinguir falhas de produto de falhas de componente. As primeiras (analisadas por FTA) são as descrições de como os clientes percebem as falhas do produto. Por exemplo, o aparelho não liga. As segundas (analisadas por FMEA) são as descrições das falhas conforme a percepção do engenheiro, estando por isso ligadas aos componentes. Por exem- plo, a ignição não sendo alimentada pela corrente elétrica.

identificação dos parâmetros críticos da funções. Segundo CLAUSING (1993), os parâmetros críticos das funções são os fatores que, fixados corretamente, garantem o correto desempenho das funções. Esses fatores são obtidos pelo detalhamento da Árvore de Funções até o seu nível hierárquico mais baixo. CLAUSING (1993) ainda recomenda que os parâmetros críticos das funções sejam incluídos nas características dos mecanismos, junto com outras decisões relevantes. Como na abordagem proposta não se desdobra o produto em mecanismos, optou-se por utilizar os parâmetros críticos das funções como um dos métodos de extração das características dos componentes. Isso requer a execução do passo 8 do desdobramento da qualidade $\mathbf{e}$ tecnologia (Figura 4). Deve-se esclarecer que esse passo não existe nos desdobramentos propostos por AKAO (1996), AKAO (1990) e CHENG et al. (1995).

extração, via brainstorming, de outras decisões utilizando a experiência da equipe em produção; 


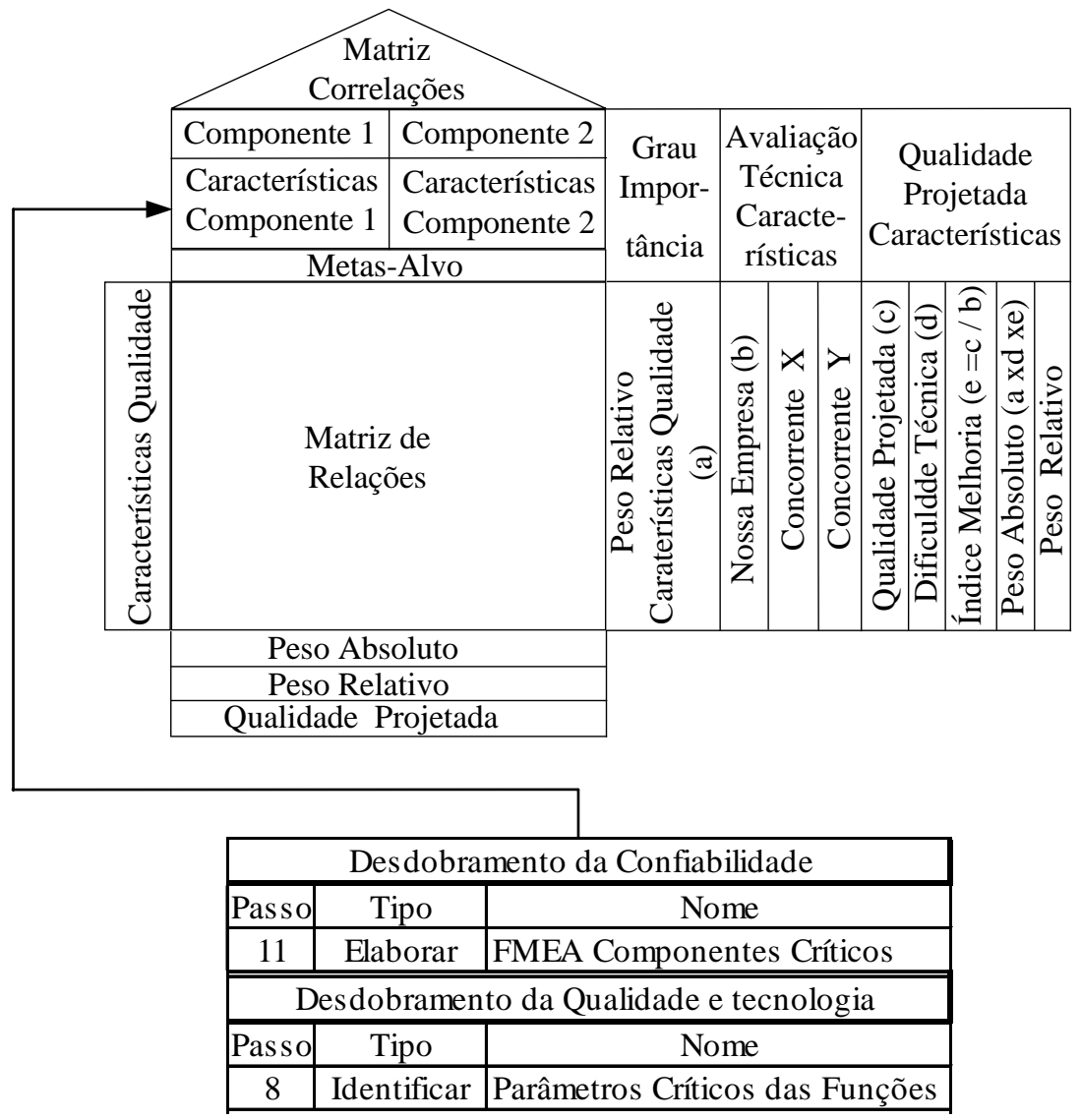

Figura 4 - Demonstração da interseção da matriz de Projeto dos Componentes com os desdobramentos analíticos

extração de outras decisões de engenharia utilizando conhecimentos de engenharia.

\subsection{Elaboração da Matriz de Processo do Componente (Piece-Part Process Matrix)}

A Matriz de Processo do Componente (PiecePart Process Matrix) tem como entrada (ou requisitos) as características dos componentes e como saída (colunas) as decisões de engenharia de processos (Figura 5). Tais decisões correspondem à definição dos parâmetros de processo. E os parâmetros de processo correspondem aos itens que são controlados para garantir o ajuste de cada processo. É importante notar que aqui se faz referência aos itens de verificação, conforme definição de SUZAKI (1993).
Na abordagem proposta, a extração dos parâmetros dos processos deve ser orientada pela FMEA dos Processos Críticos (passo 12 do desdobramento da confiabilidade. Ver Figura 5.), elaborada para aqueles processos considerados críticos. Isso porque o pleno conhecimento das causas e efeitos das falhas de cada processo ajuda a compreender como controlá-lo, como melhorá-lo e, ainda, suas limitações em função da sua tecnologia. Desse modo, o conhecimento obtido durante a elaboração da FMEA facilita a conversão das falhas do processo (qualidades negativas) em parâmetros de processo (qualidades positivas). Em tempo, os processos serão considerados críticos quando tiverem pelo menos um peso convertido das falhas de produto com valor significativo. 


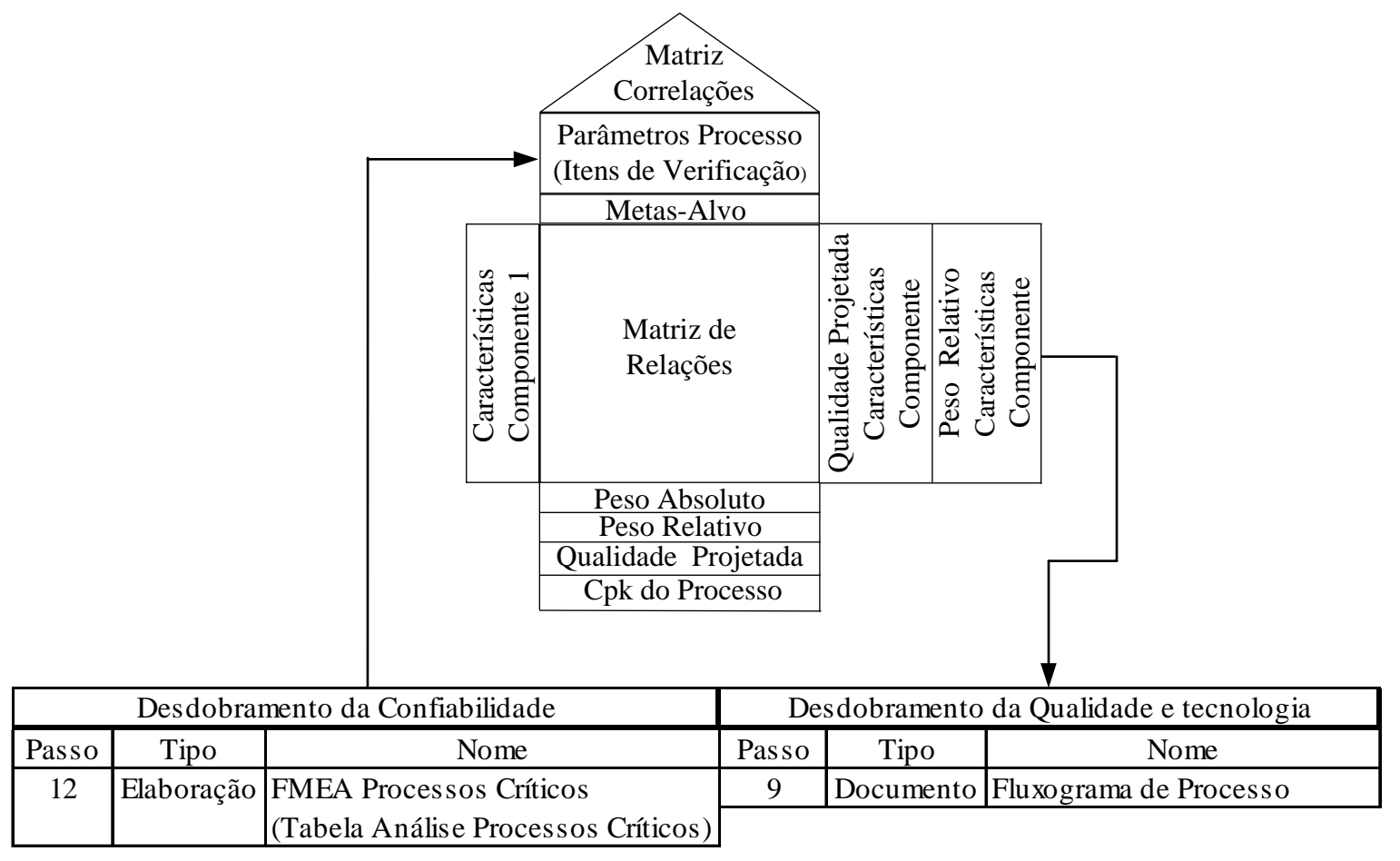

Figura 5 - Demonstração das interseções da Matriz de Processo dos Componentes com os desdobramentos analíticos

Após finalizada a elaboração de todas as matrizes de processo dos componentes, deve-se elaborar o Fluxograma de Processo (passo 9 do desdobramento da qualidade e tecnologia, Figura 5). Esse documento é o instrumento básico do planejamento do processo, pois é utilizado para definir a seqüência de operações (fluxo do processo), definir os equipamentos que serão utilizados para executar esses processos, para identificar os ajustes necessários nesses equipamentos, para determinar tempos esperados de operação em cada etapa do processo e para definir as etapas que serão automatizadas. É também nesse documento que ocorre a definição de como os parâmetros de processo serão controlados, se por itens de controle (medidos nos componentes), ou se por itens de verificação (medidos diretamente nos processos). Os itens de controle, conforme definidos por SUZAKI (1993), são aquelas características técnicas dos componentes que serão periodicamente conferidas (medidas) para controlar o ajuste dos processos. Caso a escolha recaia sobre os itens de controle, a definição de quais características dos componentes serão verificadas é facilitada pela matriz de processo dos componentes.

\subsection{Matriz de Produção dos Componentes (Operations Planning Matrix)}

Na Matriz de Produção dos Componentes (Operations Planning Matrix) executa-se o detalhamento dos processos de fabricação, com o nível de profundidade necessário para transmitir as informações ao pessoal de produção. Porém, se o detalhamento não for necessário pode-se suprimir essa matriz. O detalhamento não será necessário quando as informações definidas na matriz anterior forem suficientes para o pessoal de produção executar seu trabalho de rotina.

A entrada da matriz é composta dos processos, com seus respectivos parâmetros. A saída consiste no detalhamento dos processos. CLAUSING (1993) informa que a Matriz de 
Produção dos Componentes deve conter pelo menos as seguintes informações: providências para a manutenção dos equipamentos e treinamento de operadores, determinação do fluxo de materiais, e o conjunto dos pontos de checagem de qualidade (itens de controle ou itens de verificação, conforme a decisão tomada na matriz anterior). Pelo estudo de MUSETTI (1995), adiciona-se as seguintes informações à relação acima: determinar os dados organizacionais, determinar o ferramental, determinar as suboperações e determinar as condições de trabalho.

Porém, deve-se alertar que a saída dessa fase é maior que a saída da matriz em si. A saída da fase constitui-se no conjunto de documentos utilizados para transmitir todas as informações necessárias para a produção do produto. E nesses documentos devem constar as informações sobre os pontos de controle dos processos (itens de controle mais itens de verificação), o fluxo de produção (operações e suboperações), os equipamentos, etc. Esse conjunto de documentos envolve, então, as decisões tomadas nas outras fases do processo de desenvolvimento que, aqui, serão sintetizadas.

\section{Discussão e Conclusão}

$\mathrm{E}$ ste trabalho apresentou uma abordagem de aplicação de QFD que sintetiza duas versões dessa metodologia, o QFD das Quatro Ênfases e o QFD-Estendido. Essa síntese foi obtida pela incorporação de matrizes da primeira nas fases da segunda. Na abordagem proposta, o desenvolvimento do produto é "conduzido" pelo QFD-Estendido, aqui chamado de desdobramento do produto. Ainda nessa abordagem, a versão das Quatro Ênfases constitui-se de procedimentos que objetivam facilitar a elaboração das matrizes do desdobramento do produto. Assim, as quatro ênfases "originais" foram adaptadas para dar esse suporte, sendo aqui chamadas de desdobramentos analíticos. Mais ainda, os desdobramentos analíticos só são executados quando "solicitados" pelo desdobramento do produto, gerando pontos de interseção entre o último e os primeiros. Os pontos de interseção são os elementos das matrizes do desdobramento de produto que devem ser precedidos ou seguidos pela execução dos passos dos desdobramentos analíticos. Desse modo, o cerne da abordagem proposta está na determinação de tais pontos de interseção e na identificação da contribuição que os desdobramentos analíticos podem oferecer para a elaboração de cada elementos das matrizes do desdobramento do produto.

Acredita-se que a abordagem proposta mantém as vantagens das duas versões que lhe deram origem. Por isso, a abordagem proposta tem o potencial de proporcionar os quatro benefícios genéricos obtidos com a utilização de QFD, enumerados a seguir:

a garantia da conexão entre as decisões tomadas durante o processo de desenvolvimento de produto.

a ampliação, distribuição e nivelamento do conhecimento dos membros da equipe de QFD sobre o produto a ser desenvolvido, sobre os processos de produção e sobre as relações existentes entre ambos.

construção de um amplo corpo de conhecimento, sobre o produto e seus processos de fabricação, capaz de garantir a qualidade da tomada de decisões.

determinação das prioridades a partir da conversão de pesos.

Para proporcionar os três últimos benefícios, a abordagem proposta sistematiza (ou mesmo provoca), em função dos desdobramentos analíticos, a análise das relações existentes entre as diversas variáveis do desenvolvimento de produto. Assim, ela demonstra, de modo similar à versão das Quatro Ênfases, um grande potencial para garantir a qualidade das decisões, pela ampliação e distribuição do conhecimento acumulado pela equipe de QFD. Para proporcionar o primeiro benefício, a abordagem proposta torna explícita a cadeia hierarquizada de decisões, de modo similar ao QFD-Estendido, demonstrando um grande potencial para evitar 
desvios de foco e decisões que não obedeçam ao princípio de desdobramento.

Deve-se ressaltar que a abordagem proposta não foi ainda validada em um desenvolvimento de produto real, em função do tempo que uma aplicação como essa demandaria, e também em função da dificuldade em encontrar empresas dispostas a participarem de um trabalho como esse. A não validação da abordagem proposta faz com que as conclusões sejam baseadas em suposições sobre o seu impacto na atividade de desenvolvimento de produto. Como o QFD muitas vezes apresenta problemas exatamente na sua execução prática, esta abordagem deve ser vista com as restrições cabíveis a um trabalho teórico. Ainda assim, acredita-se na validade deste trabalho, já que uma aplicação prática deve ser precedida de uma proposta teórica.

Ainda, uma última discussão se impõe: o tempo de execução do QFD, em geral, e da abordagem proposta, em particular. Essa imposição é devida à freqüência das discussões sobre a real possibilidade do QFD diminuir o ciclo do desenvolvimento de produto, visto que muitos consideram excessivo o tempo gasto na elaboração das tabelas e matrizes que compõem essa metodologia.

Deve-se perceber que o QFD não é uma metodologia que irá automaticamente diminuir o ciclo de desenvolvimento dos produtos em todas as empresas. Tal redução depende da empresa, do tipo de produto, da equipe de desenvolvimento e de vários outros fatores. Isso porque os benefícios advindos do QFD são em grande parte dependentes de fatores relacionados à cultura organizacional, tais como trabalho em equipe, quebra de barreiras interdepartamentais, consolidação de equipes multifuncionais, delegação de autoridade e responsabilidade para a tomada de decisões (empowerment), entre outros.

Quanto ao tempo consumido com pesquisas de mercado, deve-se considerar que, hoje, é vital desenvolver produtos com a visão de marketingin, em substituição à postura tradicional de product-out, independentemente do uso do QFD. A visão de marketing-in implica em conheci- mento atualizado das necessidades dos clientes e, também, conhecimento atualizado da percepção dos clientes em relação à competitividade de nossos produtos. Por isso, a visão de marketing-in exige que as pesquisas de mercado sejam realizadas de forma permanente ou periódica, para manter tais atualizações. Se o conhecimento de mercado é mantido atualizado, pode-se agilizar a elaboração da casa da qualidade elaborando toda a tabela de requisitos dos clientes a partir do conhecimento existente na própria empresa. Aliás, LOCKAMY III \& KHURANA (1995), bem como AKAO (1990), alertam que os requisitos podem ser gerados dentro da própria empresa, pela experiência mercadológica dos seus colaboradores.

Outra questão a ser considerada é o tempo consumido com o preenchimento de tabelas e matrizes. Obtidos os conhecimentos necessários para se desenvolver o projeto, o preenchimento das matrizes com símbolos e cálculos de pesos é apenas um ato rotineiro, que não consome tempo significativo em relação ao tempo de aprendizado e difusão do conhecimento. Ou seja, no QFD, a maior parcela de tempo é despendida no aprendizado, na difusão de conhecimento e na tomada de decisões (as discussões e análises das matrizes de QFD são, na verdade, a operacionalização do aprendizado, da difusão e da tomada de decisões, não o preenchimento das matrizes). Esses três fatores são importantes e consomem tempo em qualquer desenvolvimento de produto, utilizando ou não o QFD. Por sinal, essa metodologia sistematiza tais questões, provavelmente economizando o tempo que seria desperdiçado por desvio de foco e não sistematização do trabalho.

Finalmente, pode-se argumentar que a literatura internacional cita casos reais de redução do tempo de ciclo do desenvolvimento do produto. Existem também casos em que esse tempo de ciclo aumentou. O importante, porém, dentro da visão de marketing-in é desenvolver o melhor produto (pela visão dos clientes) dentro do menor tempo de desenvolvimento possível. Se para ter o melhor produto é necessário aumentar 
o tempo de ciclo de desenvolvimento em relação a antiga postura product-out, então, o balanço adequado entre tempo de desenvolvimento de produto e qualidade deve ser uma decisão estratégica.

\section{Agradecimento}

À Fundação de Amparo à Pesquisa do Estado de São Paulo (FAPESP), pela concessão de Bolsa de Mestrado ao primeiro autor desse trabalho.

\section{Referências Bibliográficas}

ABREU, F.S.: "QFD - Desdobramento da Função Qualidade - estruturando a função qualidade”, Revista de Administração de Empresas, Vol.37, No.2, pp.47-55, 1997.

AKAO, Y.: Introdução ao desdobramento da qualidade, Trad. por Zelinda Tomie Fujikawa e Seiichiro Takahashi, Belo Horizonte, Escola de Engenharia da UFMG, Fundação Cristiano Ottoni, 1996.

AKAO, Y., ed.: Quality function deployment: integrating customer requirements into product design, Trad. por Glenn H. Mazur, Cambridge, Productivity Press, 1990.

BOOTHROYD, G.: "Simplifying the process", Manufacturing Breakthrough, No.1, pp.85-89, 1992.

CHENG, L.C.; SCAPIN, C.A.; OLIVEIRA, C.A.; KRAFETUSKI, E.; DRUMOND, F.B.; BOAN, F.S.; PRATES, L.R.; VILELA, R.M.: QFD: planejamento da qualidade, Belo Horizonte, UFMG, Escola de Engenharia, Fundação Cristiano Ottoni, 1995.

CLAUSING, D.: Total quality development: a stepby-step guide to world-class concurrent engineering, New York, ASME, 1993.

CLAUSING, D. \& PUGH, S.: "Enhanced quality function deployment”. Design and Productivity International Conference, Honolulu, 1991, pp.15-25.

HAUSER, J.R. \& CLAUSING, D.: "The house of quality”, Harvard Bussiness Review, No.3, pp.6373, 1988.
KIENITZ, O.H.: "Proposta de implantação da metodologia do quality function deployment na Mercedes-Bens do Brasil S.A.”. São Carlos, UFSCar, Dissertação de Mestrado, 170p., 1995.

KING, B.: Better designs in the half the time: implementing QFD quality function deployment in América, 3.ed, Methuen, Goal/QPC, 1989.

LOCKAMY III, A. \& KHURANA, A.: "Quality function deployment: a case study”, Production and Inventory Management Journal, Vol.36, No.2, pp.56-60, 1995.

MALLON, J.C. \& MULLIGAN, D.E.: "Quality function deployment - a system for meeting customer's needs", Journal of Construction Engineering and Management, Vol.119, No.3, pp.516-531, 1993.

MUSETTI, M.A.: "Proposta de uma metodologia de sistematização para a área de planejamento do processo em pequenas e médias empresas do ramo metal-mecânico, visando a implantação de um sistema de planejamento do processo assistido por computador (CAPP)”. São Carlos, EESC-USP, Dissertação de Mestrado, 172p., 1995.

SIVALOGANATHAN, S. \& EVBUOWAN, N.F.O.: "Quality function deployment - the technique: state of the art and future directions", Concurrent Engineering: research and applications, Vol.5, No.2, pp.171-181, 1997.

SULLIVAN, L.P.: “Quality function deployment”, Quality Progress, Vol.19, No.6, pp.39-50, 1986.

SUZAKI, K.: The new shop floor management: empowering people for continuous improvement, New York, Free Press, 1993. 


\title{
AN APPLICATION OF QFD TO INTEGRATE THE MODEL OF ENHANCED QFD AND THE MODEL BY AKAO
}

\begin{abstract}
This paper presents an approach to the application of Quality Function Deployment that brings together the Enhanced QFD and the approach developed by Akao. In this way, the proposed approach benefits from focusing, at the same time, on: parameter extraction, systematizing the decision-taking process within its matrices (Enhanced QFD); and the identification of relationships among different parameters of the product development process (QFD by Akao). The steps involved in the proposed approach are depicted and justified. Finally, we discuss the effect of QFD on time to market and the benefits of the proposed approach.
\end{abstract}

Key words: quality function deployment; quality planning; product development. 